\title{
Pediatric intracranial dural arteriovenous fistulas: age-related differences in clinical features, angioarchitecture, and treatment outcomes
}

\author{
Steven W. Hetts, MD, ${ }^{1}$ Parham Moftakhar, MD, ${ }^{1}$ Neil Maluste, MD, ${ }^{2}$ Heather J. Fullerton, MD, MAS, ${ }^{3}$ \\ Daniel L. Cooke, MD, ${ }^{1}$ Matthew R. Amans, MD, MS, ${ }^{1}$ Christopher F. Dowd, MD, ${ }^{1,3-5}$ \\ Randall T. Higashida, MD, ${ }^{1,3-5}$ and Van V. Halbach, MD ${ }^{1,3-5}$
}

Departments of ${ }^{1}$ Radiology and Biomedical Imaging, ${ }^{3}$ Neurology, ${ }^{4}$ Neurological Surgery, and ${ }^{5}$ Anesthesia and Perioperative Care, University of California, San Francisco; and 2Department of Neurology, University of California, Los Angeles, California

\begin{abstract}
OBJECTIVE Intracranial dural arteriovenous fistulas (DAVFs) are rare in children. This study sought to better characterize DAVF presentation, angioarchitecture, and treatment outcomes.

METHODS Children with intracranial DAVFs between 1986 and 2013 were retrospectively identified from the neurointerventional database at the authors' institution. Demographics, clinical presentation, lesion angioarchitecture, treatment approaches, angiographic outcomes, and clinical outcomes were assessed.

RESULTS DAVFs constituted $5.7 \%$ (22/423) of pediatric intracranial arteriovenous shunting lesions. Twelve boys and 10 girls presented between 1 day and 18 years of age; boys presented at a median of 1.3 years and girls presented at a median of 4.9 years. Four of 8 patients $\leq 1$ year of age presented with congestive heart failure compared with 0/14 patients $>1$ year of age $(p=0.01)$. Five of 8 patients $\leq 1$ year old presented with respiratory distress compared with $0 / 14$ patients $>1$ year old $(p=0.0021)$. Ten of 14 patients $>1$ year old presented with focal neurological deficits compared with $0 / 8$ patients $\leq 1$ year old $(p=0.0017)$. At initial angiography, 16 patients harbored a single intracranial DAVF and 6 patients had 2-6 DAVFs. Eight patients (38\%) experienced DAVF obliteration by the end of treatment. Good clinical outcome (modified Rankin Scale score 0-2) was documented in $77 \%$ of patients $>1$ year old at presentation compared with $57 \%$ of patients $\leq 1$ year old at presentation. Six patients (27\%) died.

CONCLUSIONS Young children with DAVFs presented predominantly with cardiopulmonary symptoms, while older children presented with focal neurological deficits. Compared with other pediatric vascular shunts, DAVFs had lower rates of angiographic obliteration and poorer clinical outcomes.
\end{abstract}

http://thejns.org/doi/abs/10.3171/2016.5.PEDS15740

KEY WORDS dural arteriovenous fistula; DAVF; vascular disorders; neurological deficit; cardiopulmonary

$\mathrm{D}$ URAL arteriovenous fistulas (DAVFs) account for approximately $10 \%$ of all intracranial shunts in children. ${ }^{9}$ DAVFs are direct arteriovenous connections in the dura, with drainage into dural sinuses or pial cortical veins. Although these rare lesions can be congenital, some studies suggest that many are acquired..$^{9,24}$ The natural history of DAVFs in neonates and children has become better known over the last several decades. Untreated lesions can lead to potentially fatal high-output cardiac failure as well as severe and irreversible neurodevelopmental delay. . $, 5,6,9-15,21,24$ Endovascular embolization is the primary treatment for DAVFs. ${ }^{3,7,24}$

In this paper we present one of the largest single-institution experiences with management of pediatric DAVFs. We compare clinical presentations, angioarchitecture, and treatment outcomes of neonates and infants with DAVFs presenting in the first year of life with those of children presenting later in life (between the ages of 1 and 18 years).

ABBREVIATIONS AVM = arteriovenous malformation; $\mathrm{CCA}=$ common carotid artery; $\mathrm{CHF}=$ congestive heart failure; $\mathrm{Cl}=$ confidence interval; $\mathrm{DAVF}=$ dural arteriovenous fistula; DSA = digital subtraction angiogram; DSM = dural sinus malformation; $m R S$ = modified Rankin Scale; NGAVF = non-Galenic pial arteriovenous fistula; OR = odds ratio; SSS = superior sagittal sinus; VOGM = vein of Galen malformation.

SUBMITTED December 26, 2015. ACCEPTED May 24, 2016.

INCLUDE WHEN CITING Published online August 19, 2016; DOI: 10.3171/2016.5.PEDS15740. 
TABLE 1. Clinical presentation and fistula angioarchitecture stratified by age at presentation

\begin{tabular}{|c|c|c|c|c|c|c|}
\hline Baseline Clinical Characteristics & All Patients & Age $\leq 1 \mathrm{Yr}$ & Age $>1 \mathrm{Yr}$ & OR & $95 \% \mathrm{Cl}$ & $p$ Value* \\
\hline No. of patients & 22 & 8 & 14 & & & \\
\hline \multicolumn{7}{|l|}{ Age } \\
\hline Mean \pm SD & $6.8 \pm 7.7 \mathrm{yrs}$ & $108 \pm 122$ days & $10.5 \pm 7.4 \mathrm{yrs}$ & & & \\
\hline Median & $1.7 \mathrm{yrs}$ & 92 days & 11.6 yrs & & & \\
\hline Range & 1 day-18.9 yrs & 1-353 days & $1.2-18.9$ yrs & & & \\
\hline Males (\%) & $12(55)$ & $5(63)$ & $7(50)$ & 1.7 & $0.21-15$ & 0.67 \\
\hline Seizures (\%) & $3(14)$ & $1(13)$ & $2(14)$ & 0.86 & $0.13-20$ & 1 \\
\hline $\mathrm{CHF}(\%)$ & $4(18)$ & $4(50)$ & $0(0)$ & $\operatorname{lnf}$ & 2.8-inf & 0.01 \\
\hline Headaches $(\%)$ & $2(9)$ & $0(0)$ & $2(14)$ & 0 & $0-3.4$ & 0.52 \\
\hline Focal neurological deficit (\%) & $10(45)$ & $0(0)$ & $10(71)$ & 0 & $0-0.25$ & 0.0017 \\
\hline Hydrocephalus (\%) & $7(32)$ & $6(75)$ & $1(7)$ & 39 & $2.2-1900$ & 0.0023 \\
\hline Respiratory distress (\%) & $5(23)$ & $5(63)$ & $0(0)$ & $\operatorname{lnf}$ & 4.4-inf & 0.0021 \\
\hline Current or prior hemorrhage (\%) & $4(18)$ & $2(25)$ & $2(14)$ & 2 & $0.11-33$ & 0.6 \\
\hline Trauma $(\%)$ & $3(14)$ & $0(0)$ & $3(22)$ & 0 & $0-2.1$ & 0.27 \\
\hline Any identified comorbidity or risk factor (\%) & $18(82)$ & $7(88)$ & $11(79)$ & 1.9 & $0.12-110$ & 1 \\
\hline \multicolumn{7}{|l|}{ Angioarchitecture (\%) } \\
\hline$>1 \mathrm{DAVF}$ & $5(23)$ & $1(13)$ & $4(29)$ & 0.36 & $0.0064-5$ & 0.61 \\
\hline$>1$ arteriovenous connection & $15(68)$ & $6(75)$ & $9(64)$ & 1.7 & $0.18-23$ & 1 \\
\hline$>10$ arteriovenous connections & $5(23)$ & $3(38)$ & $2(14)$ & 3.6 & $0.29-53$ & 0.31 \\
\hline Additional vascular lesions (non-DAVF) & $4(18)$ & $2(25)$ & $2(14)$ & 2 & $0.11-33$ & 0.6 \\
\hline Venous ectasia/varix & $11(50)$ & $5(63)$ & $6(43)$ & 2.2 & $0.28-20$ & 0.66 \\
\hline Venous reflux & $11(50)$ & $3(38)$ & $8(57)$ & 0.45 & $0.051-3.6$ & 0.66 \\
\hline Venous sinus thrombus/occlusion & $13(59)$ & $6(75)$ & $7(50)$ & 3 & $0.34-39$ & 0.38 \\
\hline Pseudophlebitic cortical venous pattern & $8(36)$ & $1(13)$ & $7(50)$ & 0.14 & $0.0028-1.8$ & 0.17 \\
\hline Venous sinus dilation & $12(55)$ & $6(75)$ & $6(43)$ & 4 & $0.45-51$ & 0.2 \\
\hline Persistent fetal venous structures & $6(27)$ & $4(50)$ & $2(14)$ & 6 & $0.54-83$ & 0.14 \\
\hline
\end{tabular}

Inf = infinite.

* $p$ values derived from Fisher's exact test.

Finally, we compare the outcomes of children with DAVFs with other pediatric intracranial arteriovenous shunts.

\section{Methods \\ Study Cohort}

In this institutional review board-approved study, a neurointerventional database was used to identify a cohort of 423 patients $\leq 18$ years of age who had undergone evaluation and treatment for intracranial arteriovenous shunts at our hospital between 1986 and 2013. Medical records and imaging reports were reviewed. Forty patients with potential DAVFs were identified. Patients who developed DAVFs subsequent to treatment of another primary intracranial arteriovenous shunting lesion (e.g., non-Galenic pial arteriovenous fistula [NGAVF] or arteriovenous malformation $[\mathrm{AVM}]$ ) were excluded. After further review of reports, the cohort was reduced to 24 patients with primary intracranial DAVFs. Of these 24 patients, 2 were excluded due to insufficient clinical or imaging data.

\section{Medical Record Review}

Baseline clinical presentation data were collected for each subject (Supplemental Table 1). Arterial and venous angioarchitectural characteristics identified from initial pretreatment angiograms were also documented (Supplemental Tables 2 and 3).

\section{Imaging Review}

Baseline cerebral digital subtraction angiograms (DSAs) with corresponding reports were available for 20 of 22 patients. Angiographic images were reviewed and scored (by S.W.H., N.M., and P.M.) according to a structured angiographic data collection tool originally developed for brain AVMs and subsequently modified to highlight features specific to DAVFs. ${ }^{4,17}$ If discrepancies between angiographic images and reports were discovered, images were reviewed and results derived from image review were used for final scoring. Two patients were scored from structured angiographic reports alone due to an inability to retrieve old images. These reports are of the same format and were authored by the same group of angiographers present for the entire study period. To exclude potential bias from inclusion of the aforementioned 2 patients, we performed a sensitivity analysis on data excluding these patients and did not find significant changes in effect sizes (data not shown). 
TABLE 2. Treatments and outcomes stratified by age at presentation

\begin{tabular}{|c|c|c|c|c|c|c|}
\hline Treatments & All Patients & Age $\leq 1 \mathrm{Yr}$ & Age $>1 \mathrm{Yr}$ & OR & $95 \% \mathrm{Cl}$ & p Value* \\
\hline \multicolumn{7}{|l|}{ Age at first treatment } \\
\hline Mean \pm SD & $6.8 \pm 7.7 \mathrm{yrs}$ & $108 \pm 122$ days & $10.5 \pm 7.4 \mathrm{yrs}$ & & & 0.0009 \\
\hline Median & $1.7 \mathrm{yrs}$ & 92 days & $11.6 \mathrm{yrs}$ & & & \\
\hline Range & 1 day-18.9 yrs & 1 day-353 days & $1.2-18.9 \mathrm{yrs}$ & & & \\
\hline Median Dx or Tx procedures (range) & $2(1-19)$ & $1(1-5)$ & $2(1-19)$ & & & $0.42 \dagger$ \\
\hline Median treatment procedures (range) & $1(0-18)$ & $1(0-5)$ & $2(1-18)$ & & & $0.22 \dagger$ \\
\hline Endovascular treatments only & $14 / 21(67 \%)$ & $5 / 8(63 \%)$ & $9 / 13(69 \%)$ & 0.74 & $0.83-7.3$ & 1 \\
\hline Any open surgical treatment & $4 / 21(19 \%)$ & $1 / 8(13 \%)$ & $3 / 13(23 \%)$ & 0.48 & $0.0080-7.7$ & 1 \\
\hline Any stereotactic radiosurgery & $2 / 21(10 \%)$ & $0 / 8(0 \%)$ & $2 / 13(15 \%)$ & 0 & $0-3.2$ & 0.5 \\
\hline Observation only & $2 / 21(10 \%)$ & $2 / 8(25 \%)$ & $0 / 13(0 \%)$ & $\operatorname{lnf}$ & 0.93-inf & 0.13 \\
\hline Procedural or periprocedural complication & $4 / 21(19 \%)$ & $1 / 8(13 \%)$ & $3 / 13(23 \%)$ & 0.48 & $0.0080-7.7$ & 1 \\
\hline \multicolumn{7}{|l|}{ Outcomes at last follow-up } \\
\hline \multicolumn{7}{|l|}{ Follow-up duration $\ddagger$} \\
\hline Mean \pm SD & $5.5 \pm 6.3 \mathrm{yrs}$ & $3.5 \pm 5.7 \mathrm{yrs}$ & $6.4 \pm 6.5 \mathrm{yrs}$ & & & 0.37 \\
\hline Median & $3.6 \mathrm{yrs}$ & 186 days & $6.1 \mathrm{yrs}$ & & & \\
\hline Range & 2 days -23.1 yrs & 2 days -14.2 yrs & 180 days -23.1 yrs & & & \\
\hline Elimination of all arteriovenous shunting & $8 / 21(38 \%)$ & $3 / 8(38 \%)$ & $5 / 13(38 \%)$ & 1 & $0.12-8.9$ & 1 \\
\hline White matter calcifications $\S$ & $2 / 11(18 \%)$ & $0 / 5(0 \%)$ & $2 / 6(33 \%)$ & 0 & $0-2.2$ & 0.45 \\
\hline Normal neurological examinationף & $6 / 16(38 \%)$ & $1 / 5(20 \%)$ & $5 / 11(45 \%)$ & 0.3 & $0.0051-4.9$ & 0.59 \\
\hline Deceased after discharge for any reason & $6 / 22(27 \%)$ & $2 / 8(25 \%)$ & $4 / 14(29 \%)$ & 0.83 & $0.059-8.2$ & 1 \\
\hline Median last mRS score (range) $)^{* \star}$ & $1(0-6)$ & $1(0-6)$ & $1(0-6)$ & & & $0.53 \dagger$ \\
\hline Good outcome (last mRS score $0-2)^{* *}$ & $14 / 20(70 \%)$ & $4 / 7(57 \%)$ & $10 / 13(77 \%)$ & 0.4 & $0.037-4.5$ & 0.61 \\
\hline
\end{tabular}

$\mathrm{Dx}=$ diagnostic, $\mathrm{Tx}=$ therapeutic.

* $p$ values are derived from Fisher's exact test unless otherwise specified.

$\dagger$ Wilcoxon log rank-sum test.

$\ddagger$ Data available for $18 / 22$ patients.

$\S$ Data available for $11 / 22$ patients.

If Data available for $16 / 22$ patients.

** Data available for $20 / 22$ patients.

DAVFs were categorized into those with single arteriovenous connections and those with multiple arteriovenous connections. Venous sinus dilation was defined as twice the expected diameter of a given dural venous sinus based on angiograms performed at our institution of children of similar ages but without arteriovenous shunting. Venous reflux was defined as any abnormal reversal of blood flow within cerebral veins or venous sinuses on DSAs. Pseudophlebitic cortical venous pattern was defined as tortuous, engorged pial veins noted during the venous phase of digital subtraction angiography.

\section{Treatment}

Patients were managed with conservative observation, endovascular intervention, a combination of endovascular and surgical intervention, or a combination of endovascular and radiosurgical intervention. Treatment and outcome data are detailed in Supplemental Table 4.

\section{Outcomes}

Two investigators (S.W.H. and N.M.) reviewed medical records from each patient's last available clinical follow-up evaluation to assess neurological status and developmental disability; any disagreements were resolved via further review and consensus. An adapted modified Rankin Scale (mRS) score of neurological disability ${ }^{28}$ for pediatric patients with brain AVMs was used to retrospectively assign each patient both baseline clinical function and final clinical function. Good clinical outcome was defined as pediatric $\mathrm{mRS}$ scores of $0-2$. Images and imaging reports from each patient's last follow-up were evaluated for residual arteriovenous shunting or new DAVF formation. Follow-up duration was calculated from initial clinical presentation to final clinical or imaging report.

\section{Statistical Analysis}

Our cohort of patients was stratified both by sex and age at presentation: neonates and infants presenting at $\leq 1$ year of age compared with older children presenting at $>$ 1 year of age (Tables 1 and 2). Student t-tests were used to compare continuous normally distributed data, Wilcoxon rank-sum (Mann-Whitney) tests were used to compare ordinal data, and Fisher's exact tests were used to compare proportions. Descriptive statistics and t-tests were calculated using Excel for Macintosh 2011 (Microsoft). Odds ratios (ORs), confidence intervals (CIs), Fisher's exact tests, and Wilcoxon rank-sum tests were calculated using Stata SE (version 12.1, StataCorp). 
TABLE 3. Comparison of pediatric DAVF outcomes in the literature

\begin{tabular}{lccc}
\hline \multicolumn{1}{c}{ Outcome } & $\begin{array}{c}\text { Current } \\
\text { Study }(\%)\end{array}$ & $\begin{array}{c}\text { Kincaid et al., } \\
2001(\%)\end{array}$ & $\begin{array}{c}\text { Walcott et al., } \\
2013(\%)\end{array}$ \\
\hline Complete AVF occlusion & $8 / 21(38)$ & $3 / 7(43)$ & $6 / 7(86)$ \\
\hline $\begin{array}{l}\text { No neurological deficit or } \\
\text { developmental delay }\end{array}$ & $7 / 20(35)$ & $2 / 7(29)$ & $7 / 7(100)$ \\
\hline Death & $6 / 22(27)$ & $2 / 7(29)$ & $0 / 7(0)$ \\
\hline
\end{tabular}

\section{Results}

\section{Demographic Information}

DAVFs were present in $5.7 \%(24 / 423)$ of the pediatric patients evaluated and treated for intracranial arteriovenous shunts at our hospital during the study period. Of the 22 patients included for further analysis, 8 presented at $\leq$ 1 year of age and 14 presented at $>1$ year of age (median age 1.7 years, range 1 day to 18.9 years; Table 1 ). Whereas 12 boys presented at a median age of 1.3 years, 10 girls presented at a median of 4.9 years. Detailed baseline demographics and clinical presentations are summarized in Supplemental Table 1.

\section{Clinical Presentation}

Clinical presentation varied by age (Table 1) but was not significantly different between boys and girls. One boy was suspected to have an intracranial arteriovenous fistula on fetal MRI in the setting of hydrops fetalis. Three patients presented as neonates $(<1$ month), 5 patients presented in later infancy ( 3 months to 1 year), and 14 patients presented later in childhood (1.2-18 years).

Neonates presented with congestive heart failure (CHF; $3 / 3)$, respiratory distress $(2 / 3)$, and hydrocephalus $(3 / 3)$. Aside from hypotonia (3/3), neurological deficits were not apparent in this very young group. No intracranial hemorrhages were identified in this group. Of 5 patients who presented between 1 month and 1 year of age, 3 had respiratory distress, 3 had hydrocephalus or macrocephaly, 2 had facial or cranial hemangiomas or venous or lymphatic malformations, 1 had seizures, 1 had developmental delay, and 2 had intracranial hemorrhage.

Of 14 patients who presented after the first year of life, clinically 2 children presented with headaches, 2 demonstrated developmental delay, 2 presented with intracranial hemorrhage, and 3 children presented with carotid cavernous fistulas following trauma. On examination, 10 presented with focal neurological deficits (cranial nerve palsies, aphasia, hemiparesis, axial weakness, facial droop, and ophthalmoplegia), 6 had cranial bruits, 2 demonstrated head and neck hemangiomas or venous or lymphatic malformations, and 1 child was macrocephalic with hydrocephalus.

Potential risk factors for intracranial DAVFs as well as comorbidities associated with significant arteriovenous shunting were identified in multiple patients. One patient had hydrops fetalis due to severe arteriovenous shunting. Obstetric complications that may have contributed to fetal CHF included maternal diabetes mellitus Type 2 and placental abruption. One patient had Cowden syndrome.
TABLE 4. Outcomes among different pediatric intracranial AVFs at our institution

\begin{tabular}{lccc}
\hline \multicolumn{1}{c}{ Outcome } & $\begin{array}{c}\text { DAVF Current } \\
\text { Study (\%) }\end{array}$ & $\begin{array}{c}\text { NGAVF } \\
2011^{17}(\%)\end{array}$ & $\begin{array}{c}\text { VOGM } \\
2003^{8}(\%)\end{array}$ \\
\hline Complete AVF occlusion & $8 / 21(38)$ & $15 / 23(65)$ & $21 / 27(78)$ \\
\hline $\begin{array}{c}\text { No neurological deficit or } \\
\text { developmental delay }\end{array}$ & $7 / 20(35)$ & $11 / 23(48)$ & $14 / 27(52)$ \\
\hline Death & $6 / 22(27)$ & $2 / 23(9)$ & $4 / 27(15)$ \\
\hline
\end{tabular}

Several patients possessed congenital vascular anomalies including a forehead angioma, eyelid and scalp hemangiomas, a lymphatic malformation of the neck and tongue, and a port wine stain.

\section{Angioarchitecture}

DAVF angioarchitecture in our cohort did not vary significantly between different age groups (Table 1). Identification of multiple DAVFs (between 2 and 6) in a single patient occurred in $29 \%$ of the patients $>1$ year old versus $13 \%$ of patients $\leq 1$ year old $(\mathrm{p}=0.61)$. Both age groups demonstrated similar proportions of patients with complex DAVFs possessing more than 1 arteriovenous connection. Common DAVF locations included the torcula $(n=9)$, transverse sinus $(n=7)$, superior sagittal sinus (SSS; $n=6)$, and cavernous sinus $(n=6)$. With regard to vascular sequelae of dural arteriovenous shunting, venous sinus dilation trended toward occurring more frequently in younger children ( $75 \%$ vs $43 \%$, respectively; $p$ $=0.2$ ) but both age groups possessed similar percentages of patients with venous ectasia, venous reflux, and venous sinus thrombosis. A pseudophlebitic cortical venous pattern secondary to venous congestion was observed more commonly in patients $>1$ year of age $(50 \%)$ as compared with patients $\leq 1$ year of age $(13 \% ; p=0.17)$. Significant differences in DAVF angioarchitecture were not observed between the male and female patients, although there was a trend toward venous reflux occurring more commonly in girls $(\mathrm{p}=0.2)$.

\section{Treatment}

Treatments, imaging outcomes, clinical outcomes, and procedural complications are detailed in Table 2 and Supplementary Table 4. Patients received between 1 and 19 endovascular, radiosurgical, or surgical procedures with a median of 2 interventions. Sixty-seven percent of our patients received endovascular treatment only. Patients presenting at $>1$ year of age trended toward more treatments than patients presenting at $\leq 1$ year (median 2 vs median $1, p=0.22$ ).

Twenty-one of 22 patients had sufficient data available at our institution with regard to DAVF treatment and were further analyzed. Transvenous and transarterial endovascular treatments employed a variety of materials: coils, 11/21 patients (52\%); particulate embolics, 8/21 patients (38\%); liquid adhesives, $8 / 21$ patients (38\%); absolute ethanol, 3/21 patients (14\%); detachable balloons, $3 / 21$ patients (14\%); and silk sutures, $1 / 21$ patients (5\%). Four patients (19\%) underwent craniotomy and resection and 2 patients 
(10\%) underwent stereotactic radiosurgery following embolization.

Procedural or periprocedural complications occurred in 4 of 21 patients (19\%), in patients 204 days, 1.3 years, 2 years, and 9.6 years old. Complication rates did not differ between patients $\leq 1$ year of age and patients $>1$ year of age or between male and female patients. Complications included access-site femoral artery stenosis following embolization, postoperative craniotomy infection following resection, catheter-induced vasospasm requiring intraarterial verapamil infusion, and nontarget coil embolization to the lungs with subsequent endovascular coil recovery.

\section{Imaging and Clinical Outcomes}

Mean follow-up was $5.5 \pm 6.3$ years with a median of 3.6 years and range of 2 days to 23.1 years. Eight (38\%) of 21 patients with complete imaging data demonstrated angiographic elimination of arteriovenous shunting at last imaging follow-up. Elimination of arteriovenous shunting was achieved at similar rates $(38 \%)$ in patients $\leq 1$ year of age and patients $>1$ year of age. Girls had higher rates of arteriovenous shunting elimination (50\%) as compared with boys (27\%), although this difference was not significant $(\mathrm{p}=0.38)$. Patients who presented at age $>1$ year and female patients more often demonstrated imaging sequelae of "melting brain syndrome" such as cerebral white matter calcifications, which is likely a result of chronic venous hypertension secondary to arteriovenous shunting ( $2 / 6$ vs $0 / 5$, respectively), but these differences also did not reach significance $(\mathrm{p}=0.45)$.

Clinical outcomes did not vary significantly between age groups or by sex. The median mRS score at last follow-up for all surviving patients was 1 . Male and female patients both demonstrated a median mRS score of 1 at last follow-up, as did patients who presented at $\leq 1$ year and those who presented at $>1$ year. Good clinical outcome (pediatric $\mathrm{mRS}$ score of 0-2 at last clinical followup) was documented in 10/13 patients $>1$ year of age at presentation as compared with 4/7 patients $\leq 1$ year of age at presentation $(\mathrm{p}=0.61)$. At last follow-up, $6 / 22$ patients (27\%) were deceased: 2 neonates died within 1 week of treatment and 4 older children died after a delay of several years, including 1 who died of recurrent leukemia and the others as a sequelae of the DAVF.

Whereas 6/11 patients (55\%) with venous reflux had poor outcomes (pediatric mRS score 3-6), all 10 patients without venous reflux had good outcomes (pediatric $\mathrm{mRS}$ score $0-2, p=0.01$ ). There was also a more frequent association between venous reflux and poor outcomes among boys $(5 / 6,83 \%)$ versus girls $(1 / 5,20 \%, \mathrm{p}=0.08)$. Three (43\%) of 7 patients with torcular involvement had poor outcomes. There was no significant difference in outcomes in the presence of venous reflux between patients $\leq$ 1 year of age $(3 / 3,100 \%)$ compared with patients $>1$ year of age $(3 / 8,37 \%, p=0.18)$, which may be related to the small number of patients with this rare disease.

\section{Discussion}

DAVFs are defined by an aberrant connection between a dural artery and either a dural venous sinus or cortical vein. The complexity of these lesions can vary substantially, with some DAVFs having only a single arteriovenous connection and others having numerous arteriovenous connections. Although pediatric DAVFs may arise early in utero, analogous to a vein of Galen malformation (VOGM), some of these lesions appear to be acquired later in development or postnatally. The presence of mature arterial and venous architecture in most DAVFs, for example, suggests that DAVFs are most likely acquired at some point following the third month of intrauterine life. Massive venous sinus enlargement is a hallmark of congenital DAVFs not observed in adult-acquired DAVFs, underscoring their origins in the fetus wherein sinuses are normally large and may remain large due to high fistulous flow, instead of regressing. It is theorized that venous thrombosis during fetal life promotes the formation of 1 or more DAVFs prior to birth, analogous to venous sinus thrombosis in adults leading to DAVF formation. ${ }^{9}$ Postnatally, however, thrombocytopenia due to platelet consumption along the surface of huge clots in enlarged venous sinuses can complicate DAVF treatment. ${ }^{22}$

There are two major hypotheses explaining the pathogenesis of DAVFs. One hypothesizes that DAVFs arise from "dormant" channels between the external carotid circulation and the venous pathways within the dura mater that open in response to venous hypertension. ${ }^{2,19}$ The other suggests that new vascular channels are stimulated by angiogenic factors that arise directly from sinus thrombosis or as a result of tissue hypoxia. ${ }^{16,26,27,29,30,32}$ Although the etiology of DAVFs remains to be elucidated, it is likely that the combination of arterialized turbulent blood, progressive venous sinus stenosis/hypertension, and venous reflux results in progressive veno-occlusive disease that can lead to the melting brain syndrome, as noted in several of our patients (Fig. 1). In the melting brain syndrome, chronic venous hypertension leads to irreversible brain injury with white matter calcifications and encephalomalacia. Usually bilateral and symmetric, melting brain syndrome corresponds to a regional decrease in cerebral blood flow caused by the retrograde venous hypertension. ${ }^{22}$

Risk factors for development of DAVFs may be genetic or environmental. Some arteriovenous shunts have been linked to chromosomal abnormalities, including hemorrhagic hereditary telangiectasia and neurofibromatosis Type I (as in Case 7 in our cohort; Supplemental Table 1). ${ }^{20,22,29}$ Many of our patients with DAVFs also presented with peripheral hemangiomas or venous or lymphatic malformations. Hypercoaguable states are also a risk factor for sinus thrombosis and subsequent formation of DAVFs, including leukemia (Case 17, Fig. 2; Supplemental Table 1) and smoking. Trauma-as in Cases 18, 20, and 22 -is another well-known risk factor for the development of DAVFs.

We identified 24 patients with imaging-confirmed DAVFs from a cohort of 423 patients with intracranial arteriovenous shunts, for a total incidence of $5.7 \%$. This is lower than the incidence of approximately $10 \%$ reported by Garcia-Monaco et al. ${ }^{9}$ The true incidence of this rare disease is unknown. Five (23\%) of 22 patients in our cohort had multiple separate (multifocal) DAVFs as compared with $3.5 \%$ of patients in the Garcia-Monaco 

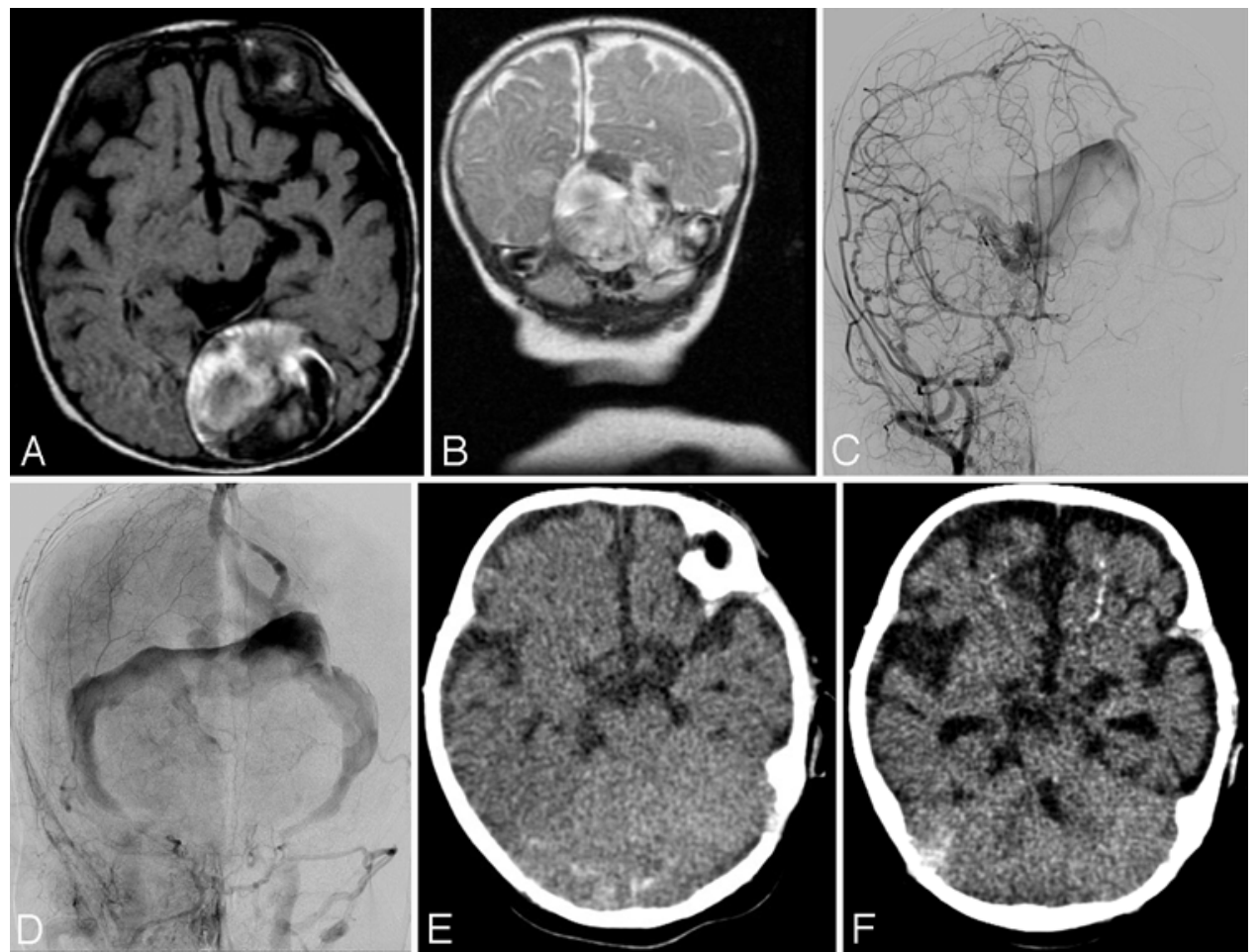

FIG. 1. Case 4. Imaging in this patient demonstrated extensive multifocal high-risk DAVFs involving the torcula and left transverse sinus, as shown on the axial T1-weighted MR image (A), coronal T2-weighted MR image (B), arterial phase right common carotid artery (CCA) angiogram (anteroposterior projection; C), and venous phase right CCA angiogram (anteroposterior projection; D). The initial axial CT scan demonstrated no evidence of calcifications (E). The long-term follow-up CT scan demonstrated melting brain syndrome, including calcifications and encephalomalacia in the setting of chronic venous hypertension related to the incompletely treated extensive multifocal high-risk DAVF (F).

series. ${ }^{9}$ In contrast to the Kincaid et al..$^{21}$ and Garcia-Monaco ${ }^{9}$ DAVF series, in our study multifocal DAVFs were observed more often in patients $>1$ year of age at presentation as compared with patients $\leq 1$ year of age. Some of this may be due to the high complexity and size of the 3 neonatal DAVFs in our series. For example, in Case 3 (Supplemental Table 2), it was difficult to judge whether that patient had a single large torcular DAVF or instead had adjacent but separate torcular and superior vermian DAVFs.

Our data suggest that neonates and infants up to 1 year of age predominantly present with cardiorespiratory symptoms from high-output arteriovenous shunting and underresorption hydrocephalus due to intracranial venous hypertension. Older patients tended to present with neurological symptoms as opposed to cardiorespiratory symptoms. Younger children more commonly presenting with CHF, respiratory distress, and hydrocephalus, and older children more commonly presenting with focal neurological deficits is consistent with other pediatric DAVF series $s^{9,21,24}$ and also parallels the clinical presentations in $\mathrm{NGAVF}^{17}$ and VOGM. ${ }^{23}$ As with adults, the most predictive feature for future neurological manifestations was the presence or absence of cerebral venous reflux. ${ }^{6}$ In our analysis, more than half of patients with venous reflux had poor outcomes. All patients without venous reflux had good outcomes.

With regard to DAVF location, our results were similar to those in other major series with the most common sites being the torcula, SSS, transverse sinus, and cavernous sinus (Fig. 3). ${ }^{9,21,24}$ DAVFs away from the torcula should theoretically have a better chance of favorable outcomes, as there will be at least 1 normal sinus for the brain to drain. In our series, $43 \%$ of patients with torcular involvement had poor outcomes.

Multiple classification systems exist for pediatric DAVFs. Lasjaunias' classification system included 3 types of shunts, including the dural sinus malformation (DSM), infantile-type DAVFs, and adult-type DAVFs. ${ }^{24}$ DSMs can further be subdivided into 2 types. The first type of DSM involves the posterior sinus with or without the torcula, with giant dural lakes and slow-flow mural arteriovenous shunting. Spontaneous thrombosis may further restrict cerebral venous drainage and subsequently lead to intraparenchymal hemorrhagic infarction. The second type of DSM involves the jugular bulb with otherwise normal sinuses but associated with a high-flow sigmoid sinus AVF. The prognosis is excellent with embolization treatment. ${ }^{24}$ In our series, there were 4 patients with DSMs, 2 died during the study, and 2 met their respective developmental milestones (ages 4 months and 16 years).

Infantile dural arteriovenous shunts are high flow and low pressure. The sinuses are large and patent with no lakes. Clinical onset is observed in the first few years of life and the shunts are initially well tolerated. Progressive symptoms (symptoms of raised intracranial pressure and venous ischemia) develop at a later age and initially re- 


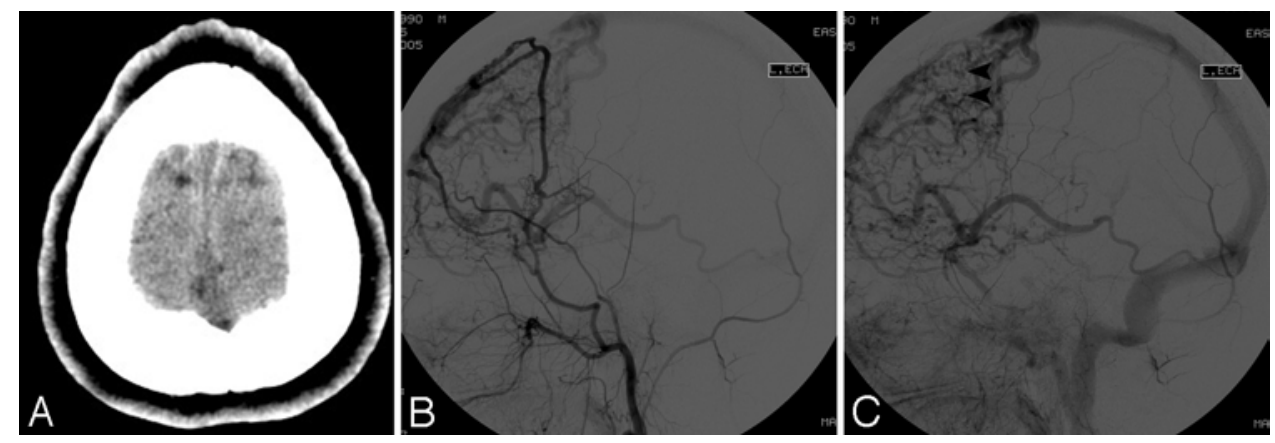

FIG. 2. Case 17. Neuroimaging in this patient demonstrated DAVF formation following SSS thrombosis. The axial contrastenhanced CT scan shows SSS thrombosis (A). An external carotid artery angiogram (arterial phase, lateral projection) is given (B), and the external carotid artery angiogram venous phase, lateral projection (C) demonstrates pseudophlebitic venous drainage (arrowheads).

spond to partial embolization. The long-term prognosis is poor with neurological deterioration in early adulthood. ${ }^{24}$ In our series, there were a total of 6 patients with infantiletype DAVFs (1 child demonstrating both infantile- and adult-type fistulas). On last follow-up only 1 child was meeting their developmental milestones. Two of the children were deceased, 1 had a poor neurological examination result, and the other 2 required special assistance.

Adult-type DAVFs are present in all age groups and almost all of them are located in the cavernous venous plexus. Post-embolization outcome is excellent. ${ }^{24}$ In our series, 10 patients demonstrated adult-type DAVFs and all but 1 were meeting their respective developmental milestones (1 child was deceased due to leukemia).

Endovascular intervention is the mainstay of DAVF treatment. ${ }^{21}$ Surgery and radiosurgery are usually reserved for cases in which endovascular therapy fails or is not possible due to difficult access to the fistula site. We favor the use of coils to treat DAVFs in young children over the use of liquid embolic agents, given the potential for nontarget embolization of liquid embolics to the lung or elsewhere. Close collaboration with pediatric cardiology is essential, not only for evaluation of right-to-left shunting, raising the potential for systemic nontarget embolization, but also for evaluation of DAVF treatment effect on CHF. Nontarget embolization of liquid embolic agents in neonates and infants, especially in the setting of CHF, can be clinically devastating. Nontarget embolization of coils to the lungs can also occur, but coils are potentially retrievable. In some cases performing embolization solely with coils is
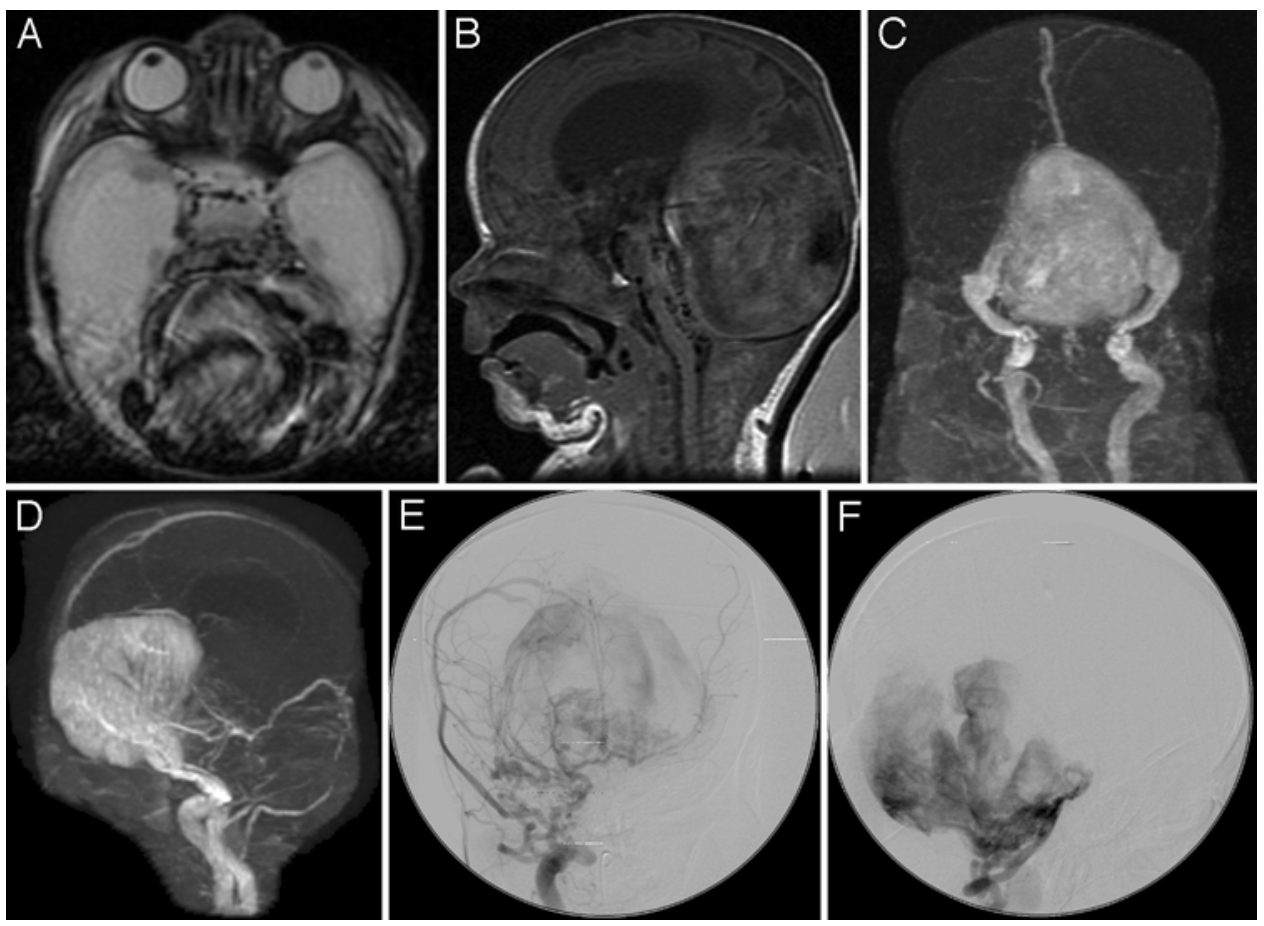

FIG. 3. Case 2. Neonate with CHF and massive torcular DAVF. A: Axial T2-weighted MRI. B: Sagittal T1-weighted MRI. C: MR venogram, anteroposterior projection. D: MR venogram, lateral projection. E: CCA angiogram, anteroposterior projection. F: Vertebral artery angiogram, lateral projection, demonstrating the torcular DAVF with multiple feeders. 
unrealistic and a combination of coils and liquid embolic agents are needed to stop flow at the fistulous point. With the introduction of ethylene vinyl copolymer, several reports both in children and adults have demonstrated successful results with acceptable complication rates. ${ }^{6,31}$ The relatively long time over which ethylene vinyl copolymer is deposited, however, leads to relatively high fluoroscopyrelated x-ray doses.

Despite advances in embolization techniques, endovascular treatment of pediatric DAVFs remains challenging. The neurointerventionalist must account for the presence of high-flow fistulas, tortuous intracranial feeding arteries, a small femoral artery access site, limitations in the volume of contrast, and risk of general anesthesia in a critically ill neonate. Due to small total blood volumes and coexistent CHF, surgery is also risky in neonates. Stereotactic radiosurgery has limited ability to induce regression of large caliber fistulas, and from a practical standpoint, frame placement is not possible in young patients with open cranial sutures. Our overall approach for the treatment of DAVFs is similar to our approach to other pediatric vascular shunts (NGAVFs, VOGMs). ${ }^{8,23}$ We favor delaying treatment until after the first several months of life unless CHF or signs of venous hypertension necessitate early intervention. Due to the significant morbidity and mortality associated with these lesions and possibility of recruitment of secondary shunts, our goal is to eradicate the fistula site. However, as noted by Kincaid et al., ${ }^{21}$ complex multifocal dural shunts cannot be immediately cured by current embolization techniques because complete occlusion of all the involved sinuses would result in severe venous outflow restriction. In patients with complex multifocal DAVFs, endovascular treatment is staged with periods of observation generally aimed at symptomatic relief.

At the last clinical or imaging follow-up evaluation, $8 / 21$ patients $(38 \%)$ in our cohort demonstrated complete elimination of arteriovenous shunting, 7/20 (35\%) had no neurological deficit or developmental delay, and 6/22 patients $(27 \%)$ were deceased. Kincaid et al. ${ }^{21}$ reported elimination of arteriovenous shunting in $3 / 7$ patients $(43 \%)$, no neurological deficit or developmental delay in $2 / 7$ patients (29\%), and death in $2 / 7$ patients $(29 \%)$. On the other hand, Walcott et al. $^{33}$ reported elimination of arteriovenous shunting in nearly all their patients $(6 / 7,86 \%)$, no neurological deficit or developmental delay in any of their patients $(7 / 7,100 \%)$, and no deaths (Table 3$)$. Treatment in the Kincaid et al. and Walcott et al. series was almost exclusively endovascular, with 1 exception in the Walcottt et al. series that used combined endovascular/surgical treatment. The Walcott et al. study concluded that treatment is effective in the obliteration of DAVFs in children and is well tolerated, with patients having excellent prognoses. Most of the children in that series were older and were stable clinically on presentation. Our study and the Kincaid group, however, include more neonates and infants who were less stable clinically on presentation. Furthermore, the Walcott et al. study did not report the complexity and angioarchitecture of their DAVFs, making direct comparisons difficult. The similarity between results from our center and the Kincaid group suggests that DAVF remains a challenging diagnosis to treat in children. In their long-term experience with pediatric DAVFs, Lasjaunias et al. ${ }^{25}$ noted that some DAVFs are lethal even 10 years after onset, indicating the caution with which we must approach our decisions. Long-term follow-up should contextualize optimistic case reports about these lesions. ${ }^{25}$

Compared with other pediatric intracranial AVF patient groups studied at our institution, our DAVF cohort had lower rates of complete AVF occlusion, lower rates of children with no neurological deficit or developmental delay at last clinical follow-up, and higher rates of death at last known follow-up (Table 4). ${ }^{8,17}$ It is also sobering to note that patients with DAVFs presenting in childhood are more likely to have de novo formation of additional DAVFs later in life. ${ }^{18}$

\section{Conclusions}

Similar to other intracranial arteriovenous shunting lesions in children, DAVFs are more likely to present with cardiorespiratory distress and hydrocephalus in neonates and infants $\leq 1$ year of age and with focal neurological deficits in patients $>1$ year of age. Given the complex angioarchitecture of these lesions, morbidity of these lesions remains high. Long-term outcomes are generally worse for children with DAVFs as compared with other types of intracranial arteriovenous fistulas. If symptomatic, treatment appears warranted to prevent the long-term sequelae of venous hypertension.

\section{Acknowledgments}

This study was supported by NIH T32 training grant no. NIBIB T32 EB001631 to Dr. Moftakhar.

\section{References}

1. Albright AL, Latchaw RE, Price RA: Posterior dural arteriovenous malformations in infancy. Neurosurgery 13:129-135, 1983

2. Aminoff MJ: Vascular anomalies in the intracranial dura mater. Brain 96:601-612, 1973

3. Andreou A, Ioannidis I, Nasis N: Transarterial balloon-assisted glue embolization of high-flow arteriovenous fistulas. Neuroradiology 50:267-272, 2008

4. Atkinson RP, Awad IA, Batjer HH, Dowd CF, Furlan A, Giannotta SL, et al: Reporting terminology for brain arteriovenous malformation clinical and radiographic features for use in clinical trials. Stroke 32:1430-1442, 2001

5. Barnwell SL, Halbach VV, Higashida RT, Hieshima G, Wilson CB: Complex dural arteriovenous fistulas. Results of combined endovascular and neurosurgical treatment in 16 patients. J Neurosurg 71:352-358, 1989

6. Cognard C, Casasco A, Toevi M, Houdart E, Chiras J, Merland JJ: Dural arteriovenous fistulas as a cause of intracranial hypertension due to impairment of cranial venous outflow. J Neurol Neurosurg Psychiatry 65:308-316, 1998

7. Cognard C, Januel AC, Silva NA Jr, Tall P: Endovascular treatment of intracranial dural arteriovenous fistulas with cortical venous drainage: new management using Onyx. AJNR Am J Neuroradiol 29:235-241, 2008

8. Fullerton HJ, Aminoff AR, Ferriero DM, Gupta N, Dowd CF: Neurodevelopmental outcome after endovascular treatment of vein of Galen malformations. Neurology 61:1386-1390, 2003

9. Garcia-Monaco R, Rodesch G, Terbrugge K, Burrows P, Lasjaunias P: Multifocal dural arteriovenous shunts in children. Childs Nerv Syst 7:425-431, 1991 
10. Halbach VV, Higashida RT, Hieshima GB, Goto K, Norman D, Newton TH: Dural fistulas involving the transverse and sigmoid sinuses: results of treatment in 28 patients. Radiology 163:443-447, 1987

11. Halbach VV, Higashida RT, Hieshima GB, Reicher M, Norman D, Newton TH: Dural fistulas involving the cavernous sinus: results of treatment in 30 patients. Radiology 163:437-442, 1987

12. Halbach VV, Higashida RT, Hieshima GB, Rosenblum M, Cahan L: Treatment of dural arteriovenous malformations involving the superior sagittal sinus. AJNR Am J Neuroradiol 9:337-343, 1988

13. Halbach VV, Higashida RT, Hieshima GB, Mehringer CM, Hardin CW: Transvenous embolization of dural fistulas involving the transverse and sigmoid sinuses. AJNR Am J Neuroradiol 10:385-392, 1989

14. Halbach VV, Higashida RT, Hieshima GB, Wilson CB, Hardin CW, Kwan E: Treatment of dural fistulas involving the deep cerebral venous system. AJNR Am J Neuroradiol 10:393-399, 1989

15. Halbach VV, Higashida RT, Hieshima GB, Wilson CB, Barnwell SL, Dowd CF: Dural arteriovenous fistulas supplied by ethmoidal arteries. Neurosurgery 26:816-823, 1990

16. Herman JM, Spetzler RF, Bederson JB, Kurbat JM, Zabramski JM: Genesis of a dural arteriovenous malformation in a rat model. J Neurosurg 83:539-545, 1995

17. Hetts SW, Keenan K, Fullerton HJ, Young WL, English JD, Gupta N, et al: Pediatric intracranial nongalenic pial arteriovenous fistulas: clinical features, angioarchitecture, and outcomes. AJNR Am J Neuroradiol 33:1710-1719, 2012

18. Hetts SW, Tsai T, Cooke DL, Amans MR, Settecase F, Moftakhar P, et al: Progressive versus nonprogressive intracranial dural arteriovenous fistulas: characteristics and outcomes. AJNR Am J Neuroradiol 36:1912-1919, 2015

19. Houser OW, Campbell JK, Campbell RJ, Sundt TM Jr: Arteriovenous malformation affecting the transverse dural venous sinus-an acquired lesion. Mayo Clin Proc 54:651-661, 1979

20. Kikuchi K, Kowada M, Sasajima H: Vascular malformations of the brain in hereditary hemorrhagic telangiectasia (RenduOsler-Weber disease). Surg Neurol 41:374-380, 1994

21. Kincaid PK, Duckwiler GR, Gobin YP, Viñuela F: Dural arteriovenous fistula in children: endovascular treatment and outcomes in seven cases. AJNR Am J Neuroradiol 22:1217-1225, 2001

22. Lasjaunias PL, ter Brugge K: Vascular Diseases in Neonates, Infants and Children. Interventional Neuroradiology Management. Berlin: Springer, 1997

23. Lasjaunias PL, Chng SM, Sachet M, Alvarez H, Rodesch G, Garcia-Monaco R: The management of vein of Galen aneurysmal malformations. Neurosurgery 59 (5 Suppl):S184S194, S3-S13, 2006 [Erratum in Neurosurgery 60 (4 Suppl 2):393, 2007]

24. Lasjaunias P, Magufis G, Goulao A, Piske R, Suthipongchai S, Rodesch R, et al: Anatomoclinical aspects of dural arteriovenous shunts in children. Review of 29 cases. Interv Neuroradiol 2:179-191, 1996

25. Lasjaunias P, ter Brugge KG, Berenstein A: Dural arteriovenous shunts, in Surgical Neuroangiography: Clinical and Interventional Aspects in Children, ed 2. Berlin: Springer, 2006, Vol 3, p 389-453

26. Lawton MT, Jacobowitz R, Spetzler RF: Redefined role of angiogenesis in the pathogenesis of dural arteriovenous malformations. J Neurosurg 87:267-274, 1997

27. Rothbart D, Awad IA, Lee J, Kim J, Harbaugh R, Criscuolo GR: Expression of angiogenic factors and structural proteins in central nervous system vascular malformations. Neurosurgery 38:915-925, 1996

28. Sanchez-Mejia RO, Chennupati SK, Gupta N, Fullerton H, Young WL, Lawton MT: Superior outcomes in children compared with adults after microsurgical resection of brain arteriovenous malformations. J Neurosurg 105 (2 Suppl):82-87, 2006

29. Shin Y, Uranishi R, Nakase H, Sakaki T: [Vascular endothelial growth factor expression in the rat dural arteriovenous fistula model.] No To Shinkei 55:946-952, 2003 (Jpn)

30. Terada T, Higashida RT, Halbach VV, Dowd CF, Tsuura M, Komai N, et al: Development of acquired arteriovenous fistulas in rats due to venous hypertension. J Neurosurg 80:884-889, 1994

31. Thiex R, Williams A, Smith E, Scott RM, Orbach DB: The use of Onyx for embolization of central nervous system arteriovenous lesions in pediatric patients. AJNR Am J Neuroradiol 31:112-120, 2010

32. Uranishi R, Nakase H, Sakaki T: Expression of angiogenic growth factors in dural arteriovenous fistula. J Neurosurg 91:781-786, 1999

33. Walcott BP, Smith ER, Scott RM, Orbach DB: Dural arteriovenous fistulae in pediatric patients: associated conditions and treatment outcomes. J Neurointerv Surg 5:6-9, 2013

\section{Disclosures}

Dr. Hetts has served as a consultant to Stryker Neurovascular and Neuravi, has direct stock ownership in Medina Medical, is a patent holder for an invention licensed to Penumbra, and has received research contracts for evaluation of imaging equipment (Siemens) or for provision of core anigography lab facilities for clinical trials not related to the work under consideration from MicroVention Terumo and Stryker Neurovascular.

\section{Author Contributions}

Conception and design: Hetts. Acquisition of data: Hetts, Moftakhar, Maluste, Dowd. Analysis and interpretation of data: Hetts, Moftakhar, Maluste. Drafting the article: Moftakhar. Critically revising the article: Hetts, Fullerton, Cooke, Halbach. Reviewed submitted version of manuscript: Hetts, Fullerton, Cooke, Amans, Dowd, Higashida, Halbach. Approved the final version of the manuscript on behalf of all authors: Hetts. Statistical analysis: Hetts. Study supervision: Dowd, Halbach.

\section{Supplemental Information \\ Online-Only Content}

Supplemental material is available with the online version of the article.

Supplemental Tables 1-4. http://thejns.org/doi/suppl/10. 3171/2016.5.PEDS15740.

\section{Correspondence}

Steven W. Hetts, Neurointerventional Radiology, University of California, San Francisco, 505 Parnassus Ave., L-352, San Francisco, CA 94143-0628. email: steven.hetts@ucsf.edu. 